\title{
Non-conservative behavior of Strontium in the Changjiang Estuary
}

\author{
ERGANG LIAN ${ }^{1}$, ZHENG LAI $^{1}$, CHENGFAN YANG ${ }^{1}, \mathrm{Ni} \mathrm{SU}^{1}$, \\ PENGFEI LiU ${ }^{1}$, JuAN XU ${ }^{1}$, SHOUYE YANG ${ }^{1 *}$
}

${ }^{1}$ State Key Laboratory of Marine Geology, Tongji University, Shanghai 200092, China

(*correspondence: syyang@tongji.edu.cn)

The ${ }^{87} \mathrm{Sr} /{ }^{86} \mathrm{Sr}$ isotope ratio in seawater has long been used as a proxy in global climate change studies. Its considerable variation over geological time is thought to be associate with the balance in inputs and outputs between radiogenic $\mathrm{Sr}$ from continental weathering and unradiogenic $\mathrm{Sr}$ from hydrothermal exchange at mid-ocean ridges[1]. However, such key issues remain contentious due to imbalance of $\mathrm{Sr}$ sources. Recent field observations and experimental evidences have demostrated that riverine particulate material dissolution is likely to partially account for the imbalance between $\mathrm{Sr}$ sources to the ocean[2]. Moreover, nonconservative behavior of $\mathrm{Sr}$ has been observed in world large estuaries[2-5], which is thought to modify both flux and isotopic composition of $\mathrm{Sr}$ delivered to the ocean. The reactive mechanism behind has attracted much more interest and remains poorly constrained.

Here we present ${ }^{87} \mathrm{Sr} /{ }^{86} \mathrm{Sr}$ isotope data of water, suspended particulate, and sediment samples collected from a typical transect across the Changjiang Estuary and the East China Sea shelf. The deviations bewteen the observed and calculated two-component mixing ${ }^{87} \mathrm{Sr} /{ }^{86} \mathrm{Sr}$ ratios are significantly higher than the measurement error $( \pm 25 \mathrm{ppm})$, with a mean value of $154( \pm 18) \mathrm{ppm}$. This suggests that $\mathrm{Sr}$ is not strictly conservative and the sediment-water reaction plays an important role in Sr geochemistry. The quantitative estimates further indicate that, on a catchment scale, there exists small but considerable differences in both flux and isotopic composition of $\mathrm{Sr}$ in the Changjing estuary. Our findings also support the "Boundary Exchange" hypothesis, where significant realease of elements from riverine particulate material will greatly affect the maine elemental budgets.

[1] Palmer and Edmond (1989) Earth Planet. Sci. Lett. 92(1): 11-26. [2] Jones et al. (2012) Earth Planet. Sci. Lett s. 355356: 51-59. [3] Andersson et al. (1994) Earth Planet. Sci. Lett. 124(1): 195-210. [4] Jones et al. (2014) Earth Planet. Sci. Lett. 395: 91-100. [5] Xu and Marcantonio (2004) Geochim. Cosmochim. Acta. 68(12): 2649-2657. 